Review Article

\title{
Feasibility of surgical procedures of invasive thymoma invading the neighbouring organs
}

\author{
Ajay Kumar, Jiang Ge Ning* \\ Department of Thoracic Surgery, Shanghai Pulmonary Hospital of Tongji University, Shanghai, China
}

Received: 24 May 2019

Revised: 08 May 2019

Accepted: 11 May 2019

\section{*Correspondence: \\ Dr. Jiang Ge Ning, \\ E-mail: jgnwp@aliyun.com}

Copyright: (c) the author(s), publisher and licensee Medip Academy. This is an open-access article distributed under the terms of the Creative Commons Attribution Non-Commercial License, which permits unrestricted non-commercial use, distribution, and reproduction in any medium, provided the original work is properly cited.

\begin{abstract}
Thymomas are the commonest anterior mediastinal compartment neoplasm, which constitutes about 20 and $50 \%$ respectively of all mediastinal and anterior compartment tumors occurring in the adult population. The various staging systems of thymomas have been defined on the basis of the degree of invasiveness. According to the WHO classification, there are six histological types of thymic epithelial tumors. The most important prognostic factor is the stage according to Masaoka's system. The treatment of thymomas involves combinations of surgery, radiation, and chemotherapy. The determination of which combination is chosen is reflected mostly by the stage of the disease. In the case of invasive disease, radiation therapy is often used as adjuvant treatment. Although invasive thymoma commonly infiltrates neighbouring mediastinal structures, its extension into the superior vena cava (SVC) and consequent SVC occlusion are rare. In this kind of cases, the urgent removal of the thymoma and radical resection of the tumour infiltrating the SVC represents the reasonable option.
\end{abstract}

Keywords: Invasive thymoma, Thymoma surgery, Multimodality therapy

\section{INTRODUCTION}

Thymomas are rare neoplasm which arise from thymic tissue and develops in the anterior mediastinum, predominantly they grow quite but are malignant and have high potential to invade locally as well as systemic metastases. ${ }^{1,2}$ The most common location for ectopic thymomas is the superior and posterior mediastinum, but might also be found in rare locations such as the base of the skull, intrapericardially, in the lung parenchyma and in the pleural cavity. ${ }^{3-6}$

The annual incidence of thymomas is only 0.15 cases per 100,000 people but it is the most prevalent tumor of the anterior mediastinum. It is also documented in the literature that they have an association with autoimmune and systemic diseases like myasthenia gravis, collagen- vascular disease, pancytopenia and hypogammaglobulinemia. ${ }^{7,8}$

Most of the patients reported are between the age of 4060 years at the time of diagnosis with an equal number of males and females. Because of the high CT screening rate, a more asymptomatic disease presentation can be expected but still, $1 / 3^{\text {rd }}$ of the cases have an asymptomatic presentation. The most common symptoms are obscure chest discomfort and cough. Symptoms like shortness of breath, chest pain, dyspnoea, pleural effusion, myasthenia gravis, SVC syndrome, and phrenic nerve paralysis are seen in locally advanced or disseminated thymoma because of involvement of local structures. $^{2,9,10} \mathrm{SVC}$ syndrome is also a rare presentation, it is even uncommon with stage III or IV. ${ }^{11,12}$ The patients with thymoma have been found to also have 
paraneoplastic syndromes, the most common of which is myasthenia gravis. Many studies have also suggested that the patients having a diagnosis of thymoma are at an increased risk of development of second primary malignancies, with a reported frequency ranging from 8 to $28 \% .^{13,14}$ In literature, distant metastasis of the thymomas are very rare but because of their high potential of invasion and anatomic relation they usually invade the lungs, pericardium, large vessels (least common site of invasion but can present as SVC syndrome). ${ }^{15}$

For the early stage of disease surgical resection is the mainstay of treatment while multidisciplinary therapies (a combination of Chemotherapy, radiotherapy, surgery) are used for advanced stage or recurrent disease. If the disease is invasive in nature then chemotherapy can be applied as induction and adjuvant treatment while radiotherapy is prescribed as an adjuvant treatment only. Nonthymoma histology, Masoka stage III to IV, incomplete resection had shown a significant effect on OS (overall survival) and DFS (disease-free survival). ${ }^{16,17}$

Complete resection of the thymus and neighbouring areolar tissue using an en bloc resection was proposed by ITMIG (The International Thymic Malignancy Interest Group).$^{18}$ The most common postoperative failure was a local recurrence. The complete resection patients show a lower recurrence rate than the incomplete patients which improves their overall survival. In general, chemotherapy is used as induction chemotherapy as it's been reported that preoperative chemotherapy increases the R0 resection rate while after complete resection postoperative chemotherapy is not considered because commonly chemotherapy is used only in gross or inoperable disease. When we talk about PORT (Postoperative radiotherapy), in general, it is used for local control in Masaoka-Koga stage IV ${ }^{19-25}$ Even though PORT is used frequently during clinical practice but its indication for Masaoka-Koga stage I to III thymic tumors is controversial if the complete resection was performed. As most of the studies are in favor of complete resection alone for Masaoka-Koga stage I to III thymic tumor but still there are some researches that show the benefit from PORT. ${ }^{26,27}$

\section{STAGING OF THYMOMAS}

It is necessary to inform an American Joint Committee on Cancer/Union for International Cancer Control (AJCC/UICC) validated stage classification system for thymic tumors. This will allow for consistent universal nomenclature facilitating multinational collaborative clinical research. The staging system nomenclature must describe the anatomic extent of disease and it conforms to the tumour, node, metastasis. This is considered that this kind of system will allow consistency in international stage classification.

There have been almost 15 different classifications for the staging of thymoma had been introduced but Masaoka stage been followed the most. Masaoka staging consists of invasion to neighbouring structures, metastatic spread, and thymic capsule integrity. It was proposed in 1981and later updated in 1994 named as Masaoka-Koga system which is used later on. ${ }^{28-30}$

\section{PATHOLOGIC CLASSIFICATION}

The WHO histologic classification of thymomas and thymic carcinomas was first presented in 1999 which was later updated in 2004. This update clears the confusion created by previous classification. ${ }^{31}$ Of all thymic malignancies, the thymic carcinoma accounts for less than $1 \%$ but they are very aggressive. Their metastasis has been seen in bone, liver, lymph node while the thymomas generally just invade the neighbouring organs. The subtypes of carcinoma include undifferentiated, sarcomatoid, squamous cell, basaloid, mucoepidermoid, lymphoepithelioma and papillary.

The literature has reported that 10 year OS rate of thymoma is excellent (90\%-95\%) especially with type A, $\mathrm{AB}$, and $\mathrm{B} 1$ and a 5-year survival rate of $75 \%, 70 \%$, and $48 \%$ in $\mathrm{B} 2, \mathrm{~B} 3$, and thymic carcinoma respectively. ${ }^{32}$

\section{SURGERIES FOR THYMOMA}

To reach the maximum cure rate complete resection is the mainstay of treatment. Complete resection consists of the en bloc resection of the thymic gland and surrounding mediastinal areolar tissue. ${ }^{15,33,34}$ To gain the complete resection it is essential to remove and reconstruct the major vital structures (aorta, SVC, innominate vein). The phrenic nerve can be resected if it shows unilateral involvement but in case of the limited pulmonary reserve, severe $\mathrm{MG}$, the phrenic nerve should be protected. ${ }^{19}$ According to literature overall survival is directly associated with complete resection, therefore, careful preoperative planning is necessary. For stage, I, II, III, and IV the 10 year OS after complete resection is $90 \%$, $70 \%, 55 \%$, and $35 \%$ respectively with a recurrence rate of $3 \%, 16 \%$, and $26 \%$ for stage I, II, and III respectively. ${ }^{18}$

According to literature overall survival is directly associated with complete resection, therefore, careful preoperative planning is necessary. For stage, I, II, III, and IV the 10 year OS after complete resection is $90 \%$, $70 \%, 55 \%$, and $35 \%$ respectively with a recurrence rate of $3 \%, 16 \%$, and $26 \%$ for stage I, II, and III respectively. Several research has shown that $\mathrm{R} 0$ resection rate is increased up to $72 \%$ after preoperative chemotherapy compared to surgery alone which has $50 \%$ and $25 \%$ for stage III and IVa tumors respectively.

\section{Early stage thymoma}

As Masaoka stage I, II can be differentiated by CT imaging but it is pointless to differentiate them because the treatment guideline is complete resection for both the 
stages. The surgery includes complete en-bloc resection which includes tumor rection, complete thymectomy with surrounding mediastinal fat save the phrenic nerve if not involved or there is no intrapleural spread. ${ }^{35}$

For pathologic stage I thymoma most recommended treatment is complete resection as they show an excellent 10 year OS while adjuvant radiation therapy after resection of non-invasive encapsulated tumors shows no effect. If on pathology, there is capsular invasion found in stage II thymoma then complete resection is supplemented with adjuvant radiotherapy even though the prospective trial is not present but still, it is considered as standard care. $^{36,37}$

\section{Locally advanced thymomas}

The local invasion of thymoma can be seen on CT during preoperative planning and Stage III can be diagnosed from there. While the fine marginal invasion to neighbouring organs like lungs and pericardium can be found at the time of mediastinal exploration an extra surgical resection is recommended until the CT shows the clear margin between tumor and neighbouring structures. $^{38}$

When there is no clear invasion seen on CT with large mass $(>8-10 \mathrm{cms})$ but it looks like adherent to adjacent organs then they should be treated as stage III. It is also proposed that if the tumor size is operable in stage III then patients should be administered with induction therapy and a follow-up reassessment CT later on the surgical they can be considered. There are several studies that showed improved survival when induction is used in combination. ${ }^{26,39,40}$

\section{Surgery after induction therapy}

The usual approach is sternotomy as it gives enough exposure for large tumors (stage III). Anterior thoracotomy with the trans-sternal extension (clamshell) will be considered if there is the presence of pulmonary hilar involvement. If there is involvement of lungs, pleura or pericardium then involved part have to resect with enbloc and for the involvement of parenchyma en-bloc upper lobectomy is needed.

MG patients show significant morbidity with phrenic nerve resection. In such patients, according to their lung function and performance status can do tumor debulking to protect the phrenic nerve and mark the residual tumor for post-op radiotherapy ${ }^{38}$ A 5 and 10 year OS rate of $77 \%$ and $59 \%$ were reported by Yagi et al after extended resection of thymoma which also includes great vein resection. $^{15}$

Even though it's rare, resection of the aorta or innominate artery can be considered with prosthetic reconstruction if the invasion to the great artery is limited and complete resection of the disease will be done. ${ }^{38}$

\section{Stage IVA disease}

Cisplatin-based combination chemotherapy with followup assessment CT is used to check the possibility of surgical therapy if the patient's performance status is excellent and disease is having limited pleural based metastasis. This approach can help to improve the DFS of the patient. $^{39,40}$

It is rare to perform pleuropneumonectomy even in selective stage IVA patients it's only acceptable with a 5year survival of $75 \% .{ }^{38}$ A careful inspection of the parietal pleural surface is necessary during surgery because many time it's been seen that there is smaller occult metastasis droplet beside the larger pleural based metastasis. This process had been in cases after chemotherapy where there is no evidence on CT scan. Till now in stage III or IVA disease, the benefits of debulking is not clear. ${ }^{41}$

\section{Multimodality treatment}

If the tumor size becomes unresectable then multimodality approach is to treat it most commonly seen in Masaoka III, IVa, and IVb Thymomas. In research by Bretti and colleagues Masaoka stage III patients show increased radical resection rate( $46 \%$ to $65 \%$ ) it was also increased in Masaoka stage Iva patients $(0 \%$ to $20 \%$ after combination with neoadjuvant. In their research chemotherapy regimens were CDDP + VP16 (cisplatin and etoposide), four cycles each and for irradiation, they administer a total dose of $30 \mathrm{~Gy}$ in three weeks. As their result shows a significant increase in radical resection rate soon after induction chemotherapy can be proposed to increase surgical resectability and survival. ${ }^{42,43}$

Lucchi and colleagues also reported the same results (improved the resectability rate and survival) in their research by using multimodality treatment. ${ }^{26}$ The used surgery, neoadjuvant chemotherapy and postoperative radiotherapy in different combination. They used $60 \mathrm{~Gy}$ and 45 Gy adjuvant irradiation for complete and incomplete resection respectively. Chemotherapy was done every 3 weeks which consist of etoposide, cisplatin, and epidoxorubicin.

Kim and colleagues conducted a prospective study on 22 patients. The used induction chemotherapy consists of prednisone, doxorubicin, cyclophosphamide and cisplatin, surgery, radiotherapy and consolidation chemotherapy. Their study shows DFS in 18 patients at median follow-up (50.3 months). The OS at 5 and 7 year was $95 \%$ and $79 \%$ respectively. The key point of multimodality treatment was significantly increased survival rate with low morbidity. ${ }^{38,44,45}$

\section{Role of octreotide}

Octreotide is the somatostatin (SST) octapeptide analogue which shows the ability to inhibit thymic 
epithelium proliferation in vitro and the various subtype of SST have been found in the thymus. ${ }^{46,47}$ Thymic hyperplasia and thymic tumors can be differentiated by radiolabeled octreotide SST (indium 111)) scintigraphy, there is positive uptake of indium-111 had been seen in patients treated by octreotide supplemented with prednisolone. $^{48}$

A 16 patients series of Palmieri et al showed 15 months median survival and response rate of $37 \%$ (1 CR, $5 \mathrm{PR}$ ) when patients were treated by subcutaneous octreotide (1.5 mg daily).

Another study of 38 patients was done by Eastern Cooperative Oncology Group they also used the subcutaneous octreotide (1.5 $\mathrm{mg}$ daily) and prednisone was added to nonresponsive patients. The results showed a response rate of $10.5 \%$ (4 PRs) in patients where octreotide was used alone while it $31.6 \%$ (2 CRs, 10 PRs), in patients where octreotide was used with prednisone. Prednisone has a lympholytic effect that can diminish tumor size without affecting the underlying epithelial component.

\section{DISCUSSION}

Even though thymomas are rare tumors but they have long term prognosis if they are resectable. This rarity of the tumor makes it more difficult to study and define a standard set of prognostic factors. The data of thymoma researches majorly depends on the case series. Even though the use of WHO histologic classification has increased but it couldn't define the clinical course and treatment because there are multiple studies that report that complete resection and tumor stage are independent. ${ }^{49-51}$ While others had said that there is better prognosis with smaller tumor size, initially MG was also considered as a good prognostic factor but later got rejected. $^{52}$

Especially in patients with advanced thymoma not eligible for immediate resection, induction therapy is recommended. ${ }^{53}$ Surgical resection should be part of multimodality therapy including chemotherapy and in some cases adjuvant radiotherapy to decrease the risk of recurrence and improve survival. ${ }^{26,54}$ These neoadjuvant treatment indications were not influenced by the new TNM-staging system.

The most common site of invasion for thymomas are its neighbouring organs (heart, large vessels and lungs) and of then the invasion to superior vena cava and right atrium is rare. In various studies, surgical therapy is recommended even for the SVC and RA invasion as well. ${ }^{55,56}$ The aim of such surgeries is to achieve the blood flow from BVC to RA and complete resection which can be done by extra-anatomical grafts or cleaning of RA and SVC from tumor bulk. For grafting, we can use expanded polytetrafluoroethylene (PTFE), autologous vein, autologous or bovine pericardium while the complication of kinking and flexion is there with long conduits. Usually, an analogous pericardial $\mathrm{Y}$ shape conduit is used for SVC and BVC reconstruction. Patients showed good graft patency after 40 months follow-up.

The en bloc resection is exigent to increase the survival outcome of the patient even though radiotherapy and chemotherapy or both are also effective too. Because of the invasive potential of the tumor arterial and venous wall resections are also necessary.

In most reported cases of surgical resection of invasive thymoma with intracardiac extension, cardiopulmonary bypass is required as was in the study by Lim and Shen. ${ }^{57}$ In case of partial resection, non-adhesive atrium tumour, preoperative radiotherapy, transient cava-pulmonary shunt. $^{58-61}$ the tumor resection was performed without cardiopulmonary bypass. Almost 50\% of cases (total 19 cases) were alive at 6 months follow-up. ${ }^{62}$ A favorable prognosis can be achieved by a combination of successful resection with chemo-radiotherapy.

\section{CONCLUSION}

Although thymomas are rare they should be always taken into consideration when there is a patient presenting with an enlarged mediastinum. In conjunction with the history and physical examination, imaging techniques, including echocardiography, are essential in the diagnosis and preoperative evaluation of thymomas.

The excellent long-term survival of patients demonstrated with surgical resection with thymoma is encouraging and complete surgical resection should be done wherever possible to affect a long-term cure. In locally advanced thymomas cisplatin-based combination chemotherapy produces objective responses in $50-90 \%$ of treated patients. This has to lead the way to a multimodality approach to such patients which includes initial chemotherapy (or chemoradiotherapy) followed by surgical resection, when feasible, and radiation therapy.

Radiotherapy can be recommended for thymic carcinoma with or without the presence of invasion. Unresectable thymic tumors should undergo core needle biopsy or open biopsy to confirm tissue diagnosis. For these tumors, neoadjuvant chemotherapy can be followed by consideration of surgical resection (or radiation therapy alone for unresectable disease) and possible postoperative radiation therapy for residual disease. Because of the lack of data from adequate-sized, prospective trials, strong consideration must be made for enrollment of patients with the advanced disease into available clinical trials.

\section{Funding: No funding sources \\ Conflict of interest: None declared \\ Ethical approval: Not required}




\section{REFERENCES}

1. Cowen D, Richaud P, Mornex F, Bachelot T, Jung GM, Mirabel X, et al. Thymoma: results of a multicentric retrospective series of 149 nonmetastatic irradiated patients and review of the literature. FNCLCC trialists. Fédération Nationale des Centres de Lutte Contre le. Cancer Radiother Oncol 1995;34:9-16.

2. Wright CD. Management of thymomas. Crit Rev Oncol/Hematol. 2008;65:109-20.

3. Maclean G, Guberman A, Giulivi A. Late pseudoexacerbation of myasthenia gravis due to ectopic Thymoma invading lower cranial nerves, Can J Neurol Sci, 1990;17(1):46-8.

4. Mirra M, Zanella M, Bussani R, Falconieri G. Intrapericardial thymoma: report of two incidental autopsy cases and review of the literature, Arch Pathol Lab Med. 1997;121(1):59-63.

5. Bassermann R. Intrapulmonary Thymoma. Thoraxchir Vask Chir. 1975;23(1):14-20.

6. Fushimi H, Tanio Y, Kotoh K. Ectopic thymoma mimicking diffuse pleural mesothelioma: a case report. Hum Pathol. 1998;29(4):409-10.

7. Hon C, Chui WH, Cheng LC, Shek TW, Jones BM, $\mathrm{Au}$ WY. Thymoma associated with keratoconjunctivitis, lichen planus, hypogammaglobinemia, and absent circulating B cells. J Clin Oncol. 2006;24:2960-1.

8. Miyakis S, Pefanis A, Passam FH, Christodulakis GR, Roussou PA, Mountokalakis TD. Thymoma with immunodeficiency (Good's syndrome): review of the literature apropos three cases. Scand J Infect Dis. 2006;38:314-9.

9. Sperling B, Marschall J, Kennedy R, Pahwa P, Chibbar R. Thymoma: a review of the clinical and pathological findings in 65 cases. Can J Surg. 2003;46:37-42.

10. Wilkins KB, Sheikh E, Green R, Patel M, George S, Takano $\mathrm{M}$ et al. Clinical and pathologic predictors of survival in patients with thymoma. Ann Surg 1999;230:562-72.

11. Froudarakis ME, Tiffet O, Fournel P, Briasoulisc E, Karavasilisc V, Cuilleretet $\mathrm{J}$, et al. Invasive thymoma: a clinical study of 23 cases. Respiration. 2001;68:376-81.

12. Fujimura S, Kondo T, Handa M, Shiraishi Y, Tamahashi N, Nakada T. Results of surgical treatment for thymoma based on 66 patients. J Thorac Cardiovasc Surg. 1987;93:708-14.

13. Muller-Hermelink HK, Marx A. Thymoma. Curr Opin Oncol. 2000;12:426 -33.

14. Tsuchiya M, Asakura H, Yoshimatsu H. Thymic abnormalities and autoimmune diseases. Keio J Med. 1989;38:383-402.

15. Yagi K, Hirata T, Fukuse T, Yokomise H, Inui K, Ike $\mathrm{O}$ et al. Surgical treatment for invasive thymoma, especially when the Superior Vena Cava is invaded. Ann Thorac Surg. 1996;61:52I-4.
16. Kelly RJ, Petrini L, Rajan A, Wang Y, Giaccone G Thymic malignancies: from clinical management to targeted therapies. J Clin Oncol. 2011;29(36):48207.

17. Hejna M, Haberl I, Raderer M. Nonsurgical management of malignant thymoma. Cancer. 1999;85:1871-4.

18. Detterbeck FC, Parsons A. Thymic tumors: a review of current diagnosis, classification, and treatment. In: Patterson GA, Cooper JD, Deslauriers J, et al, (editors). Thoracic and esophageal surgery. Philadelphia: Elsevier, 2008: 1589-1614.

19. Detterbeck F, Youssef S, Ruffini E, Okumura M. A review of prognostic factors in thymic malignancies. J Thorac Oncol 2011;6:S1698-704.

20. Kondo K, Monden Y. Therapy for thymic epithelial tumors: a clinical study of 1,320 patients from Japan. Ann Thorac Surg. 2003;76:878-84.

21. Tomaszek S, Wigle DA, Keshavjee S, Fischer S, Thymomas: review of current clinical practice. Ann Thorac Surg. 2009;87:1973-80.

22. Falkson CB, Bezjak A, Darling G, Gregg R, Malthaner R, Maziak DE, et al. The management of thymoma: a systematic review and practice guideline. J Thorac Oncol. 2009;4:911-9.

23. Loehrer PJ Sr, Jiroutek M, Aisner S, Aniser J, Green M, Thomas CR Jr. et al. Combined etoposide, ifosfamide, and cisplatin in the treatment of patients with advanced thymoma and thymic carcinoma: an intergroup trial. Cancer. 2001;91:2010-5.

24. Rena O, Papalia E, Maggi G, Oliaro A, Ruffini E, Filosso PL, et al. World Health Organization histologic classification: an independent prognostic factor in resected thymomas. Lung Cancer. 2005;50:59-66.

25. Kundel Y, Yellin A, Popovtzer A, Pfeffer R, Symon Z, David A. et al. Adjuvant radiotherapy for thymic epithelial tumor: treatment results and prognostic factors. Am J Clin Oncol. 2007;30:389-94.

26. Lucchi M, Ambrogi MC, Duranti L, Basolo F, Fontanini G, Angeletti AA, et al. Advanced stage thymomas and thymic carcinomas: results of multimodality treatments. Ann Thorac Surg 2005;79:1840-4.

27. Nakahara K, Ohno K, Hashimoto J, Maeda H, Miyoshi S, Sakurai M, et al. Thymoma: results with complete resection and adjuvant postoperative irradiation in 141 consecutive patients. J Thorac Cardiovasc Surg. 1988;95:1041-7.

28. Detterbec FC, Asamura H, Crowley J, Falkson C, Giaccone G, Grioux D, et al. The IASLC/ITMIG thymic malignancies staging project: development of a stage classification for thymic malignancies. J Thorac Oncol. 2013;8(12):1467-73.

29. Masaoka A, Monden Y, Nakahara K, Tanioka T Follow-up study of thymomas with special reference to their clinical stages. Cancer. 1981;48(11):248592.

30. Koga K, Matsuno Y, Noguchi M, Mukai K, Asamura H. A review of 79 thymomas: 
modification of staging system and reappraisal of conventional division into invasive and noninvasive thymoma. Pathol Int. 1994;44(5):359-67.

31. Mu“ller-Hermelink HK, Engel P, Kuo TT, Tumours of the thymus. In: Travis WD, Brambilla E, Mu“llerHermelink H (ed). World Health Classification of Tumours, Pathology \& Genetics: Tumours of the Lung, Pleura, Thymus and Heart. Lyon, France: IARC Press; 2004: 146-248.

32. Chen G, Marx A, Chen WH, Yong J, Puppe B, Stroebel P, et al. New WHO histologic classification predicts prognosis of thymic epithelial tumors: a clinicopathologic study of 200 thymoma cases from China. Cancer. 2002;95(2):420-9.

33. Maggi G, Giaccone G, Donadio M, Ciuffreda L, Dalesio O, Leria G, et al. Thymomas. A review of 169 cases, with particular reference to results of surgical treatment. Cancer. 1986;58:765-76.

34. Regnard JF, Magdeleinat P, Dromer C, Dulmet E, de Montpreville V, Levi JF, et al. Prognostic factors and long-term results after thymoma resection: a series of 307 patients. J Thoracic Cardiovascular Surg. 1996;112:376-84.

35. Port JL, Ginsberg RJ. Surgery for thymoma. Chest Surg Clin North Am. 2001;11:421-37.

36. Curran WJ, Kornstein FJ, Brooks JJ, Andrew, T. Turrisi Invasive thymoma: the role of mediastinal irradiation following complete or incomplete surgical resection. J Clin Oncol. 1988;6:1722-7.

37. Pollack A, Komaki R, Cox JD, Ro JY, Oswald MJ, Shin DM, et al. Thymoma: treatment and prognosis. Int J Radiat Oncol Biol Phys. 1992;23:1037-43.

38. Venuta F, Rendina EA, Longo F, De Giacomo T, Anile M, Mercadante E, et al. Long-term outcome after multimodality treatment for stage III thymic tumors. Ann Thorac Surg. 2003;76:1866-72.

39. Macchiarini P, Chella A, Ducci F, Rossi B, Testi C, Bevilacqua G, et al. Neoadjuvant chemotherapy, surgery and postoperative radiation therapy for invasive thymoma. Cancer. 1991;68:706-13.

40. Berruti A, Borasio P, Gerbino A, Gorzegno G, Moschini T, Tampellini $M$, et al. Primary chemotherapy with adriamycin, cisplatin, vincristine and cyclophosphamide in locally advanced thymomas: a single institution experience. $\mathrm{Br} \mathrm{J}$ Cancer. 1999;81:841-5.

41. Kohman LJ. Controversies in the management of malignant thymoma. Chest. 1997;112:296-300.

42. Bretti S, Berruti A, Loddo C, Sperone P, Casadio C, Tessa M, et al. Multimodal management of stages III-IVa malignant thymoma. Lung Cancer. 2004;44:69-77.

43. Jacot W, Quantin X, Valette S, Khial F, Pujol JL. Multimodality treatment program in invasive thymic epithelial tumor. Am J Clin Oncol. 2005;28:5-7.

44. Huang J, Riely GJ, Rosenzweig KE, Rusch VW. Multimodality therapy for locally advanced thymomas: state of the art or investigational therapy? Ann Thorac Surg. 2008;85:365-7.
45. Huang J, Rizk NP, Travis WD, Seshan VE, Bains MS, Dycoco J, et al. Feasibility of multimodality therapy including extended resections in stage IVA thymoma. J Thorac Cardiovasc Surg. 2007;134:1477-83.

46. Ferone D, van Hagen PM, van Koetsveld PM, Seshan VE, Bains MS, Dycoco J, et al. In vitro characterization of somatostain receptors in the human thymus and effects of somatostatin and octreotide on cultured thymic epithelial cells. Endocrinology. 1999;140:373-80.

47. Ferone D, van Hagen MP, Kwekkeboom DJ, van Koetsveld PM, Mooy DM, Lichtenauer-Kaligis E, et al. Somatostatin receptor subtypes in human thymoma and inhibition of cell proliferation by octreotide in vitro. J Clin Endocrinol Metab. 2000;85:1719-26.

48. Lastoria S, Vergara E, Palmieri G, Acampa W, Varrella $\mathrm{P}$, Caracò $\mathrm{C}$, et al. In vivo detection of malignant thymic masses by indium-111-DTPA-DPhe1-octreotide scintigraphy. J Nucl Med. 1998;39:634-9.

49. Blumberg D, Port JL, Weksler B, Delgado R, Rosai J, Bains MS, et al. Thymoma: a multivariate analysis of factors predicting survival. Ann Thorac Surg. 1995;60:908-13.

50. Okumura M, Ohta M, Tateyama H, Nakagawa K, Matsumura A, Maeda H, et al. The World Health Organization histologic classification system reflects the oncologic behavior of thymoma: a clinical study of 273 patients. Cancer. 2002;94:62432.

51. Regnard JF, Magdeleinat P, Dromer C, Dulmet E, de Montpreville V, Levi JF, et al. Prognostic factors and longterm results after thymoma resection: a series of 307 patients. J Thorac Cardiovasc Surg. 1996;112:376-384.

52. de Perrot M, Liu J, Bril V, McRae K, Bezjak A, Keshavjee SH. Prognostic significance of thymomas in patients with myasthenia gravis. Ann Thorac Surg. 2002;74:1658-62.

53. Spaggiari L, Casiraghi M, Guarize J. Multidisciplinary treatment of malignant thymoma. Curr Opin Oncol. 2012;24:117-22.

54. Rajan A, Giaccone G. Treatment of advanced thymoma and thymic carcinoma. Curr Treatment Options Oncol. 2008;9:277-87.

55. Belmadani K, Amahzoune B, Selkane C, Boulahya A, el Fakir Y, al Bouzidi A, et al. Invasive thymoma extending into the superior vena cava and the right atrium: a case report and review of the literature. Ann Cardiol Angeiol (Paris) 2001;50(4):217-23.

56. Aladdin M, Bozlar U, Turba UC, Kron IL, Ahmed $\mathrm{H}$, Hagspiel KD. Mediastinalthymoma invading the superior vena cava and the right atrium. Acta Cardiol. 2007, 62(5):517-8.

57. Lim KE, Shen TC. Surgical Treatment of an Invasive Thymoma with Intracaval and Intracardiac Extension. Acta Cardiol Sin. 2017;33:204-6. 
58. Futami S, Yamasaki T, Minami R, Matasuba K, Inoue $\mathrm{K}$, Nishimoto $\mathrm{S}$, et al. Intracaval and intracardiac extension of malignant thymoma. Intern Med. 1993;32:257-60.

59. Gleeson RE, Price R, Nicholson AG, Pastorino U. Invasive thymoma extending to the right atrium: excision without cardiopulmonary bypass. J Cardiovasc Surg. 1997;38:429-31.

60. Ichimura H, Usui S, Okazaki H, konishi T, Osaka M, Jikuya T, et al. Excision after chemoradiotherapy of invasive thymoma extending into the right atrium: report of a case. Surg Today. 2006;36:534-7.
61. Dursun M, Sarvar S, Cekrezi B, Kaba E, Bakir B, Toker A Cardiac metastasis frominvasive thymoma via the superior vena cava; cardiac MRI findings. Cardiovasc Intervent Radiol. 2008;31(2):209-12.

62. Kurata A, Hisaashi S, Ikeda N, Kuroda M. Intracaval and intracardiac extension of invasive thymoma complicated by superior and inferior vena cava syndrome. Pathol International. 2013;63:56-62.

Cite this article as: Kumar A, Ning JG. Feasibility of surgical procedures of invasive thymoma invading the neighbouring organs. Int Surg J 2019;6:2645-51. 